\title{
Política exterior y paz: ¿un juego en dos niveles?
}

REYNELL BADILLO*

\begin{abstract}
Artículo recibido: 20 de junio de 2019
\end{abstract}
Artículo aprobado: 22 de enero de 2020

Doi: https://doi.org/10.12804/revistas.urosario.edu.co/desafios/a.8012

Para citar este artículo: Badillo, R. (2020). Política exterior y paz: ¿un juego en dos niveles? Desafios, 32(2), 1-37. https://doi.org/10.12804/revistas.urosario.edu.co/desafios/a.8012

\section{Resumen}

Durante los dos periodos presidenciales de Juan Manuel Santos, la politica exterior colombiana dirigió una buena parte de sus esfuerzos a solidificar, a través del involucramiento de actores internacionales, las negociaciones que se llevaban a cabo con la otrora guerrilla de las Fuerzas Armadas Revolucionarias de Colombia (FARC-EP). En el presente texto se analiza ese proceso a través de la teoría de los dos niveles de juego (two-level game theory). Además, se considera que la organización de la politica exterior colombiana alrededor de la solidificación de los Diálogos de La Habana respondió a la necesidad de consolidar este proceso, de dotarlo de legitimidad entre la población y de garantizar la implementación de lo acordado. Así, a través de acciones concretas y delproceso de internacionalización en sí mismo se construyó una suerte de "blindaje internacional" que establece restricciones a la posibilidad de dar marcha atrás a lo establecido en el Acuerdo.

Palabras clave: internacionalización de la paz; política exterior; proceso de paz; posconflicto; teoría de los dos niveles de juego; teoría de juego; Colombia.

* Universidad de los Andes. Bogotá, Colombia. Correo electrónico: ra.badillo@uniandes. edu.co. ORCID: http://orcid.org/0000-0002-3576-8533 


\title{
Foreign Policy and Peace: A Two-level Game?
}

\begin{abstract}
During the two presidential terms of Juan Manuel Santos, Colombian foreign policy focused on solidifying, through the involvement of international actors, the negotiations that were taking place with the former guerrilla of the Revolutionary Armed Forces of Colombia (FARC-EP, after the initials in Spanish). In the present text, the author analyzes the process of internationalization of the peace process and the subsequent implementation of what was agreed upon through the two-level game theory. Thus, it is considered that the organization of Colombian foreign policy around the solidification of the Dialogues of Havana responded to the need to consolidate them, give them legitimacy among the population and guarantee the implementation of what was agreed upon. In addition, through concrete actions and the process of internationalization itself, a kind of "international armor" was built, which establishes restrictions from international politics on the possibility of reversing the provisions of the Agreement.
\end{abstract} Keywords: Internationalization of peace; foreign policy; peace process; post-conflict; two-level game theory; game theory; Colombia.

\section{Política exterior e paz: um jogo em dois níveis?}

\begin{abstract}
Resumo
Durante os periodos presidenciais de Juan Manuel Santos, a politica exterior colombiana encaminhou uma boa parte de seus esforços a solidificar, através do envolvimento de atores internacionais, as negociações que se levam a cabo com a outrora guerrilha das Forças Armadas Revolucionárias da Colômbia (FARC-EP). No presente texto se analisa esse processo através da teoria dos niveis de jogo (two-level game theory). Além disso, considera-se que a organização da política exterior colombiana ao redor da solidificação dos Diálogos de Havana respondeu à necessidade de consolidar este processo, de dota-lo de legitimidade entre a população e de garantir a implementação do acordado. Assim, através de ações concretas e do processo de internacionalização em si mesmo se construiu uma espécie de "blindagem internacional" que estabelece restrições à possibilidade de dar marcha à ré ao estabelecido no Acordo.
\end{abstract}

Palavras-chave: internacionalização da paz; política exterior; processo de paz; pós-conflito; teoria dos dois niveis de jogo; teoria de jogo; Colombia. 


\section{Introducción}

La política exterior colombiana durante los dos periodos de Juan Manuel Santos estuvo enfocada, en una buena parte, en solidificar las negociaciones que se llevaban a cabo con las FARC-EP a través del involucramiento de actores internacionales. Posteriormente, con la firma del Acuerdo Final para la Terminación del Conflicto y la Construcción de una Paz Estable y Duradera, en noviembre del 2016, la comunidad internacional siguió jugando un papel fundamental en su implementación y en el apoyo a través de diferentes canales diplomáticos. Aun con la llegada al poder de Iván Duque (cuyo partido ha mostrado fuerte oposición al proceso de paz), el apoyo internacional al Acuerdo no ha mermado y, por el contrario, ha obligado al líder del ejecutivo a manejar un discurso mesurado a nivel internacional con respecto a asuntos que, en el interior del país, son cuestionados por el Centro Democrático, su partido político. ${ }^{1}$

Aunque las negociaciones de paz y el posacuerdo son asuntos esencialmente domésticos para Colombia, el involucramiento de la comunidad internacional es tal que ante decisiones que pertenecen al ámbito interno del Estado colombiano, esta ha reaccionado en favor de preservar el Acuerdo. Lo anterior puede evidenciarse con la respuesta que tuvieron las seis objeciones que el presidente Iván Duque realizó a la Ley Estatutaria de la Jurisdicción Especial para la Paz (JEP). ${ }^{2} \mathrm{La}$ ONU y las

\footnotetext{
1 Para ejemplificar esto puede observarse el discurso del presidente Duque en el Foro de París sobre la Paz. En este, el actual primer mandatario colombiano afirmó: "Le hemos pedido al sistema multilateral que nos ayude, y hemos recibido la asistencia de Naciones Unidas para que los proyectos productivos funcionen, para que las inversiones en bienes públicos en áreas rurales sean exitosas y también para monitorear la forma como vamos a proteger una paz duradera en Colombia" (El Espectador, 2018a). Asimismo, la presión internacional ejercida por la comunidad internacional puede observarse en el Informe del Alto Comisionado de las Naciones Unidas para los Derechos Humanos sobre la situación de derechos humanos en Colombia durante el año 2018, en el que afirma que "el Gobierno elegido para el período 2018-2022 tendrá la responsabilidad histórica de continuar con la implementación del Acuerdo y de avanzar en la construcción de un país en paz y equitativo, donde toda la población tenga garantizado el pleno acceso a los derechos humanos" (Asamblea General de las Naciones Unidas, 2019, I.4).

2 La JEP es el componente de justicia transicional derivado del Acuerdo de Paz. La ley estatutaria objetada por el ejecutivo sirve como respaldo jurídico a su labor.
} 


\section{4 / Reynell Badillo}

embajadas de Alemania, Suecia, Bélgica, Reino Unido, Suiza, Francia, Países Bajos y Noruega expresaron su apoyo al sistema de justicia transicional (Colombia en Transición, 2019). De hecho, el respaldo internacional fue tan importante que el entonces canciller, Carlos Holmes Trujillo, viajó a Nueva York días después de presentadas las objeciones para explicar la decisión ante el Consejo de Seguridad de la ONU, la Corte Penal Internacional (CPI) y António Guterres, el secretario general (ElTiempo, 2019).

En el presente escrito, el autor pretende analizar el comportamiento de la política exterior colombiana durante los periodos presidenciales de Santos, a través de la internacionalización del proceso de paz con las FARC-EP y el involucramiento de algunos miembros de la comunidad internacional en su implementación. Para ello, primero se elaborará una breve aproximación a la teoría de los dos niveles de juego (Two-level game theory) y, en adelante, se relacionarán sus postulados con el comportamiento internacional de Colombia durante el periodo analizado. Así se concluirá que la estrategia de internacionalización del proceso y de la implementación del Acuerdo de Paz, además de servir como instrumento para consolidar las negociaciones, dotarlas de legitimidad interna y poner en marcha su implementación, fue útil para blindar los acuerdos ante potenciales saboteadores (previendo la potencial llegada al poder de un Gobierno no tan cercano a esta estrategia de terminación del conflicto).

Por tanto, lo que se argumenta es que la configuración de la política exterior de los Estados responde a incentivos a nivel doméstico y a la identificación, por parte de los tomadores de decisiones, de recursos que hacen falta y que pueden conseguirse a nivel internacional. En el caso de la internacionalización del proceso de paz, los recursos que se buscaban eran, por un lado, materiales (fondos y cooperación internacional) y, por el otro, de carácter simbólico (confianza entre las partes negociadoras y legitimidad entre la población civil). 


\section{Aproximación a la teoría de los dos niveles de juego}

Tradicionalmente la disciplina de las relaciones internacionales ha tomado como referencia los tres niveles de análisis expuestos por Waltz (1959) para estudiar la política internacional. ${ }^{3}$ A partir de esa división, con el tiempo, han surgido explicaciones del sistema internacional que asumen a los Estados como actores unitarios con incentivos externos independientes de ellos. Según estas, resulta innecesario estudiar los atributos internos de los Estados puesto que se consideran "dados" y se estudian a través de supuestos. Se piensa que los países tienen preferencias estables y similares con sus pares,y que, por lo tanto, lo que los diferencia es su posición relativa en la esfera internacional. Estas son llamadas explicaciones sistémicas y encuentran una de las primeras formulaciones en el mismo Waltz (1979).

También existen las llamadas explicaciones domésticas. Estas asumen que los determinantes de la política exterior de los Estados se encuentran dentro de estos y no en las restricciones del sistema. Los Estados no responden a las presiones del sistema, sino que lo constituyen. Aunque haya incentivos similares, los Estados responden de forma diferenciada. Dentro de las explicaciones domésticas, Moravcsick (1993) identifica tres grupos: society-centered, state-centered e intermediate level.

El primero de estos está conformado por aquellos que consideran que los colectivos sociales pueden presionar y modificar las actitudes internacionales de los Estados a través de grupos de intereses, elecciones y la opinión pública. Dentro de esta categorización pueden encontrarse los trabajos de Rosenau (1967); Hermann, Kegley y Rosenau (1987); Koch (2015); y Ramírez y Espinoza (2019). En el segundo grupo pueden ubicarse aquellos que consideran que, para comprender la política exterior del Estado, es importante centrarse en el aparato administrativo del ejecutivo debido a que este es quien formula la política exterior. Allí

\footnotetext{
3 Según este esquema, hay un primer nivel de análisis conformado por la agencia humana y su comportamiento; un segundo que se centra en la estructura interna de los Estados; y un tercero (privilegiado por Waltz) que solo se centra en la estructura del sistema internacional. Otros autores como Singer (1961) también elaboraron aproximaciones similares.
} 


\section{6 / Reynell Badillo}

podrían ubicarse los trabajos de Allison y Zelikow (1999); Goldstein (1988); Green (2001); Jung In (2006); y de Hyde y Saunders (2019). Finalmente, el último grupo consideraría que hay instituciones que se encargan de hacer coincidir al aparato administrativo del Estado y a la sociedad. Allí podrían ubicarse los trabajos de Kissinger (1966); Van Evera (1985); Eichenberg (1998); y Garcé y López (2014).

Ante esa rígida división entre niveles de análisis, Moravcsik (1993), al retomar los postulados de Putnam (1988), plantea la posibilidad de integrar al segundo y al tercer nivel en la teoría de los dos niveles de juego (theory of two-level games). En esta, se afirma que los hombres de Estado son conscientes de que deben cumplir dos responsabilidades simultáneas: formular la política exterior del Estado y actuar dentro de la política doméstica. En ese sentido, lo que hacen es ejercer una "interacción estratégica" consistente en actuar teniendo en cuenta (y, de ser posible, influenciando) las reacciones de actores tanto internacionales como domésticos.

Los hombres de Estado son, en la teoría de los dos niveles de juego, los principales actores. Por lo tanto, la estrategia elegida por este y los incentivos que tenga para actuar (domésticos o internacionales) serán primordiales para comprender las razones de su actuación. El dirigente es un agente que busca maximizar el apoyo doméstico al tiempo que maniobra la política exterior. Así, no solo importa entender los cálculos en relación con la respuesta de otros actores internacionales, sino en relación con los resultados internos o con los diversos logros individuales.

Así como la política doméstica puede utilizarse como instrumento para alcanzar fines internacionales, la política exterior puede instrumentalizarse a fin de alcanzar objetivos domésticos. Se trata de una "aproximación interactiva" porque es necesario analizar ambos niveles de juego para tener una imagen completa de la realidad. De esta forma, cuando se percibe que los recursos disponibles a nivel doméstico son insuficientes para resolver determinadas situaciones políticas, los dirigentes pueden tener un incentivo para acudir al sistema internacional e involucrar a otros actores a fin de capitalizar su apoyo a nivel interno. 
Putnam (1988) ya había antes considerado la posibilidad de reconciliar esos dos niveles de análisis y expresó que los actores tienden a realizar movimientos en espacios internacionales que pueden provocar reacciones a nivel doméstico (o viceversa) a fin de lograr objetivos que, de otra forma, no serían posibles. Así, según este autor, la teoría de los dos niveles de juego aporta un enfoque fundamental al considerar que los tomadores de decisiones están conscientes de los efectos interactivos existentes entre los niveles y que entenderlos solo desde alguno de ellos, si bien puede ofrecer facilidades teóricas, no concuerda con la realidad.

Aunque, en principio, la teoría de los dos niveles de juego fue pensada para explicar las interacciones que se presentaban durante las negociaciones internacionales, da Conceição-Heldt y Mello (2017) muestran que este planteamiento ha sido flexibilizado y aplicado al análisis de la política exterior de los Estados y de las decisiones que estos toman. Para ello, Frieden, Lake y Schultz (2013) postulan que es necesario tener en cuenta que los actores del sistema internacional tienen intereses, definidos por ellos como "aquello que los actores quieren alcanzar a través de la acción política” (p. 42), y preferencias, entendidas como la "predilección sobre los resultados que pueden resultar de la acción política” (p. 42). Lo anterior porque, en primer lugar, comprender los intereses de los Estados a la hora de formular su política exterior permite ofrecer explicaciones más comprehensivas sobre su comportamiento y, en segundo lugar, porque evidencia que los intereses de los actores, si bien pueden ser útiles para comprender por qué se comportan de determinada manera, no necesariamente ofrecen respuestas a los resultados de esas actuaciones. Se puede actuar pretendiendo un resultado específico y obtener respuestas disímiles con esa preferencia.

Sobre la manera en que pueden comprenderse las preferencias de los Estados, Frieden (1999) considera que es necesario analizarlas a la luz del comportamiento del Estado. Es decir, al analizar la forma en que un actor se comporta deberían poder inferirse las razones que lo llevan a ello. En ese mismo sentido, Alons (2007) plantea que resulta necesario no solo centrarse en los intereses del Estado, sino en los condicionantes domésticos que este pueda tener para lograrlos. 


\section{8 / Reynell Badillo}

Podrían existir actores con capacidad de veto que motivarían al Estado a hacer uso del sistema internacional para sortear las dificultades de una negociación con ellos. Lo anterior guarda relación con la idea de que el Gobierno de un Estado mantiene cierto nivel de ventaja al poder tener conocimiento tanto sobre el nivel doméstico, como del internacional (Moravcsik, 1997). Es decir, al estar al tanto del estado de cosas en ambos niveles, la toma de decisiones no puede aislarse para alguno de los dos y, por el contrario, tiende a involucrarlos a fin de conseguir sus objetivos (Betz \& Hanif, 2010).

En síntesis, la teoría de los dos niveles de juego plantea que la política exterior y la política doméstica de los Estados no deben considerarse como dos esferas aisladas, sino que, más bien, la segunda condiciona en muchos aspectos las decisiones que se toman a nivel internacional. Por tanto, los actores que toman decisiones en estos ámbitos estructuran la política exterior de forma tal que esta pueda encontrar en la esfera internacional los recursos que, a nivel doméstico, hagan falta para resolver situaciones políticas. No debería olvidarse que los Estados configuran sus intereses, en muchos casos, a partir de condicionantes domésticos y, por tanto, lo que hay es una interacción estratégica entre la política exterior y la política doméstica mediada por los actores que las diseñan. Asimismo, se plantea que, si bien los Estados tienen intereses y preferencias particulares al configurar su política exterior, es posible que los resultados obtenidos de esa interacción no necesariamente guarden relación con esos intereses, por lo que resulta necesario no solo centrarse en los resultados, sino también observar la justificación y el contexto en el que se da esa interacción.

\section{Internacionalización de la paz}

Borda y Gómez (2017) han definido la internacionalización de la paz como "un ejercicio de toma de decisiones explícito diseñado e implementado, entre otros, por los actores en conflicto y, en este caso, por los que forman parte del proceso de negociación" (p. 213). Sobre eso, vale la pena resaltar que se trata de una decisión consciente, calculada y racional tanto por parte de quienes proponen la 
internacionalización, como de los actores que aceptan participar en ella. Es decir, se parte de la consideración de que la internacionalización de la paz no era un proceso inevitable para Colombia y de que quienes participan no lo hacen ni por fuerza, ni por un prurito moral, sino que también poseen intereses que no necesariamente serán analizados en el presente texto. Así como en el pasado algunos mandatarios colombianos decidieron incluir a determinados actores internacionales a fin de que contribuyeran al desarrollo del conflicto armado a través de la entrega de tecnología y recursos económicos (Borda, 2007; Tickner, 2007), el gobierno de Juan Manuel Santos involucró a la comunidad internacional en la consecución de una paz negociada con la entonces guerrilla de las FARC-EP.

Dentro de las acciones de la comunidad internacional que permiten observar el nivel de internacionalización de los diálogos puede observarse el estatus de países garantes que ostentaron Noruega y Cuba; el de países acompañantes que tuvieron Venezuela y Chile; la actuación de la ONU como verificadora internacional; y la designación de enviados especiales por parte de Estados Unidos y de la Unión Europea (Bernie Aronson y Eamon Gilmore), entre otras. Si bien cada una de estas acciones contribuía de alguna forma a la consecución de un acuerdo final, no puede verse la intervención de todos esos actores como parte de un mismo propósito ni tampoco igual de importante en cada una de las etapas del proceso.

En adelante, se elaborará una somera clasificación a partir de tres grandes divisiones que no necesariamente abarcan toda la gama de actores que participaron (y siguen haciéndolo) en el proceso de paz y en la implementación del mismo, ni todos los objetivos con los cuales estos fueron involucrados. Algunos actores fueron importantes para consolidar el proceso de negociación; otros estuvieron más cerca de dotarlo de legitimidad y otros han sido más importantes para la implementación. Esta categorización no puede tomarse de forma rígida. Países que participaron en la consolidación del proceso de negociación pueden también dotar de legitimidad al proceso y los países que han entregado recursos pueden actuar luego dentro de la segunda categoría. 


\section{Consolidación del proceso}

Este grupo de actores está conformado por aquellos que fueron seleccionados por las partes negociadoras para poner, o mantener, en marcha los diálogos. Estos participaron a lo largo de todo el proceso y su presencia se consideraba fundamental para que los diálogos siguieran en pie. Así, pueden identificarse dos subgrupos: los países garantes y los países acompañantes.

Los países garantes, según Fisas (2013), son aquellos actores que sirven para garantizar a las partes que lo pactado será respetado por todos los que participan en la negociación. Es decir, dado que en todo escenario de confrontación los actores tienden a reducir la confianza en su contraparte, la presencia de terceros imparciales puede resultar crucial para que quienes negocian accedan a hacerlo confiando en lo pactado. En el caso estudiado, los garantes fueron Noruega y Cuba. Como lo explican Borda y Gómez (2017), en ambos casos se trata de países con credibilidad internacional por su experiencia en anteriores procesos de negociación y, además, la distancia geográfica —en el caso de Noruega - y el poco acceso de los medios de comunicación — para el caso de Cuba - resultaron cruciales para que el proceso mantuviera un mínimo de confidencialidad y no se filtrara lo acordado a la población colombiana antes de que así lo desearan las partes. La importancia de estos actores fue tal que, en un momento en el que el conflicto parecía escalar y se ponía en duda la continuación de los diálogos, ${ }^{4}$ hicieron un llamado público a continuar con la negociación (Noticias Caracol, 2015). Además, se convirtieron en sedes del proceso.

Los países acompañantes son aquellos que, según explican Borda y Gómez (2017), tienen la capacidad de influenciar las decisiones de las partes sin tener voz en los diálogos. Es decir, su actuación suele ser observada fuera de la mesa de negociación. A diferencia de los garantes, estos sí fueron escogidos por su cercanía ideológica con

\footnotetext{
4 Esto se debió, principalmente, a un ataque de las FARC-EP que dejó diez soldados muertos el 15 de abril del 2015 y a la posterior respuesta del gobierno colombiano que reactivó los bombardeos (en aquel momento suspendidos durante un mes) (Reyes, 2015).
} 
las partes. Así, en el proceso de paz colombiano estuvo Chile por representación del Gobierno y Venezuela por la afinidad ideológica que mostraba con respecto a las FARC-EP. En ese sentido, los países acompañantes balancean de alguna forma el escenario de la discusión.

La inclusión de algunos de estos países en esta etapa del proceso no solamente sirvió para profundizar la confianza de las partes negociadoras, sino que implicó que Colombia tuviera que modificar su acercamiento a Estados con los cuales había tenido desencuentros, como Venezuela y Ecuador, antes de acudir a ellos en busca de colaboración. Aunque Ecuador no hace parte formal de este grupo de países, sí manifestó abiertamente su apoyo a las negociaciones (ElEspectador, 2013a) y, posteriormente, sirvió como sede de los diálogos que entablarían el Gobierno de Juan Manuel Santos y el ELN. De la misma forma, el entonces presidente Rafael Correa sirvió como mediador entre Colombia y Venezuela cuando, en 2015, el presidente Maduro decidió cerrar la frontera (Márquez, 2015). Visto en perspectiva, como lo sugieren Pastrana y Gehring (2017), la normalización de las relaciones diplomáticas con los países vecinos en las etapas iniciales del gobierno Santos no era necesariamente un acto desconectado de las pretensiones que este tenía con respecto al proceso de negociación. Un objetivo doméstico (resolver el conflicto armado a través del diálogo) llevó a Santos a centrar su política exterior en la resolución de tensiones con los países vecinos a fin de obtener un resultado específico (lograr que estos países, por sus características particulares, fungieran como países garantes o acompañantes del proceso de paz).

Asimismo, Pastrana y Vera (2015) consideran que Santos intentó transmitir internacionalmente la imagen de Colombia como un país bisagra, capaz de mantener su alineación con Estados Unidos, pero, al mismo tiempo, capaz de ser cercano a países con los que esto podría haber generado colisiones. En ese sentido, el hecho de que el Gobierno colombiano haya apoyado el regreso de Cuba a la cumbre de las Américas es también un movimiento intencionado con objeto de "desideologizar" la política exterior y enviar mensajes de confianza a las FARC-EP en la mesa de negociaciones, así como a Venezuela. Durante la consolidación de los diálogos, Colombia buscó con su actuación internacional 
fortalecer la confianza con su contraparte en la mesa de negociaciones dado que a nivel doméstico carecía de recursos suficientes para lograrlo.

Hacer que Venezuela fuera parte de la consolidación del proceso de paz también implicaba retos para la política doméstica de Santos. En primer lugar, porque en Colombia había, de forma generalizada, un rechazo a lo que representaba el proyecto chavista para América Latina. Esto lo evidencian Tickner y Botero (2011), quienes muestran que, para esta época, Venezuela ocupaba "el más bajo nivel de simpatía" (p. 14) entre los colombianos al preguntarles por su opinión sobre países. En segundo lugar, porque las tensiones en la relación entre ambos países se mantuvieron y reemergían constantemente. Muestra de esto es el hecho de que, en el 2013, el Gobierno de Venezuela manifestó que iba a "reconfigurar" sus relaciones con Colombia luego de que Capriles visitara el país para denunciar fraude en las elecciones de ese año (RCN Radio, 2013) y, poco tiempo después, junto a Bolivia y Nicaragua, se pronunció contra la posibilidad de que Colombia colaborara con la OTAN (ElEspectador, 2013b). Ante eso, y en vista del papel que jugaba Venezuela en uno de los principales objetivos de su mandato, el Gobierno Santos tuvo una actitud conciliadora, lo que le costó críticas por parte de la oposición, que lo acusaba de "cómplice" de lo que sucedía en este país. El punto más álgido de esa difícil relación llegó con el cierre unilateral de la frontera por parte del presidente Maduro en el 2015, ante lo cual mediaron Uruguay y Ecuador, como ya fue mencionado. Como lo ponen de manifiesto Tickner, Cepeda, Rouvinski y Milanese (2015), para ese momento se empezaba a manifestar que el presidente venezolano estaba utilizando el papel de su país en las negociaciones de paz para "manipular al Gobierno de Juan Manuel Santos en otros temas sensibles de la agenda bilateral, como las relaciones fronterizas" (p. 43). ${ }^{5}$

\footnotetext{
5 La oposición colombiana, particularmente del Centro Democrático, criticó muchas veces al expresidente Santos por no confrontar directamente las actitudes de Venezuela frente al país. De hecho, el expresidente Álvaro Uribe Vélez llegó a afirmar que Juan Manuel Santos mantenía silencio frente a las acciones de Venezuela debido a que "no se atrevía a indisponerse con las FARC" (ABC Internacional, 2014), lo cual implica que, al menos la percepción desde los sectores de oposición era que, efectivamente, Venezuela estaba sacando ventaja de su posición en la mesa de negociaciones. Si bien las relaciones bilaterales no empezaron a tensionarse durante la presi-
} 
Lo anterior también puede observarse a la luz de la opinión pública. En el 2015, el 42\% de los colombianos consideraba que la intervención de Venezuela en las negociaciones era "mala" y el 23\% opinaba lo mismo de la participación de Cuba, lo que permite afirmar que, pese a que la inclusión de estos actores era un movimiento necesario para sostener los diálogos, resultaba muy difícil justificarlo a nivel doméstico, pues el Centro Democrático capitalizaba el rechazo de la población al proyecto político de estos países.

Figura 1. Opinión negativa de la intervención en las negociaciones de paz

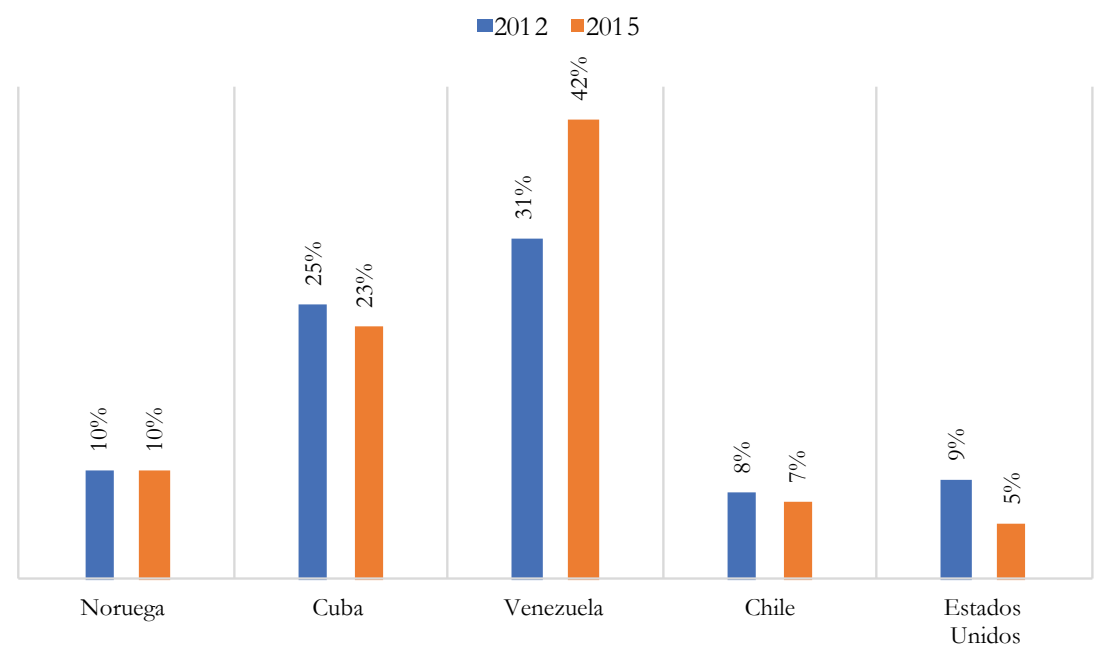

Fuente: elaboración propia a partir de los datos del proyecto Las Américas y el Mundo (2012; 2015).

Además, para el 2015, como lo demuestra la figura 2, todos los actores que intervinieron en las negociaciones de paz recibieron una calificación peor a la que habían recibido en el 2012, lo que, más allá de evidenciar calificaciones particulares sobre su labor, apuntaba más a manifestar la disminución al apoyo al proceso entre la población.

dencia de Juan Manuel Santos, sí es cierto que, como lo mencionan Bermúdez (2012) y Rodríguez (2014), por parte de Santos había una actitud más conciliadora que, aunque las explicaciones tradicionales han intentado asumir como parte de su personalidad, parece estar más relacionada con los objetivos domésticos que se perseguían. Prueba de ello podría ser que, justamente, al acabar los diálogos, hubo mucha más confrontación desde el Gobierno colombiano (CNN, 2017). 
Además, puede evidenciarse que el interés del Gobierno colombiano al involucrar a distintos actores internacionales con el objetivo de generar confianza entre las partes, si bien cumplió particularmente con este propósito, no necesariamente resultó útil en los demás aspectos de la política doméstica (particularmente en el apoyo de la población al proceso) y en otros concernientes a la política exterior (la actitud conciliadora de Juan Manuel Santos frente a las actuaciones de Venezuela sirvió de excusa para que la oposición cuestionara al mandatario).

Figura 2. Opinión positiva de la intervención de las negociaciones de paz $-2012-2015$

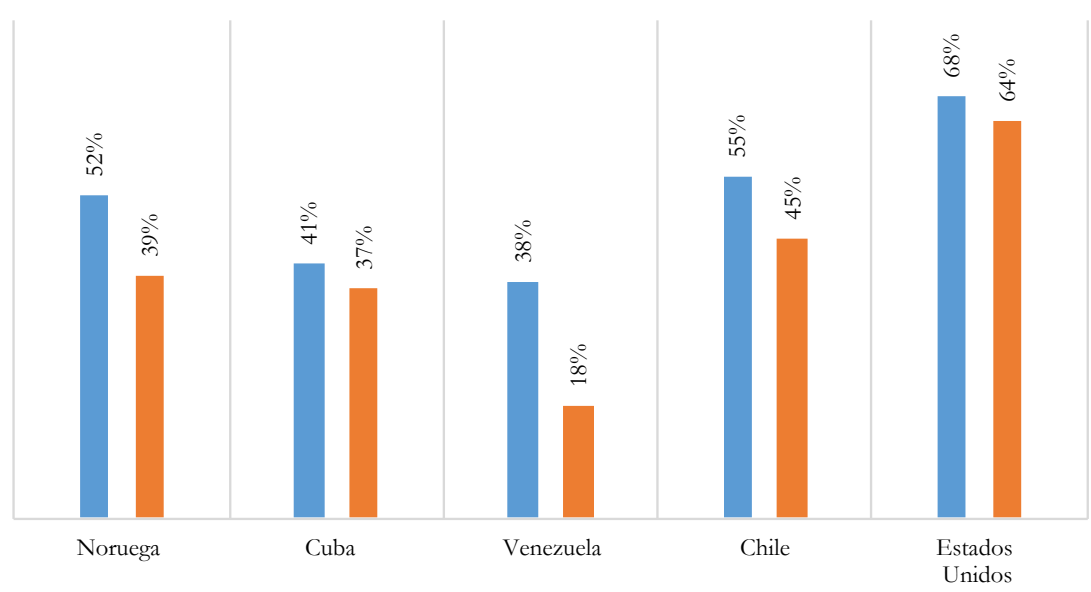

Fuente: elaboración propia a partir de los datos del proyecto Las Américas y el Mundo (2012; 2015).

\section{Influencia en la legitimidad del proceso de paz}

En este grupo se encuentran aquellos actores que, ya sea por su participación directa o por el apoyo que muestran al proceso, resultan útiles para que la población del país en el que se lleva a cabo la negociación reafirme su legitimidad. Este podría considerarse un espacio de confluencia de los actores debido a que, aunque tanto países garantes y acompañantes, como quienes participan en el proceso de implementación dedican la mayoría de sus esfuerzos a funciones distintas a esta, sus pronunciamientos públicos y el apoyo que muestran 
en diversos momentos del proceso suelen ser capitalizados a nivel doméstico por las partes. Sin embargo, en este grupo no solamente se encuentran los mencionados, sino aquellos actores que, sin ser parte directa de la negociación, han realizado gestos que son interpretados como "espaldarazos" a la consecución de un acuerdo final.

El papel de Estados Unidos puede ser leído en esa lógica: aunque no participó en la mesa de negociación directamente, fungió constantemente como un apoyo público a través de resoluciones (Noticias RCN, 2016), de apoyos económicos (Rojas, 2017), de informes dando cuenta de los resultados del apoyo estadounidense (Gómez, 2018) o, como ya se mencionó, del envío de un designado especial (Revista Semana, 2015). Asimismo, otros actores como la Comunidad de Estados Latinoamericanos y Caribeños (CELAC), la Unión de Naciones Sudamericanas (UNASUR), México, Ecuador, Brasil y varios países europeos han jugado un rol similar (aunque no con la misma influencia que Estados Unidos) y, como lo demuestra el comunicado enviado por varias embajadas europeas al presidente Iván Duque por sus objeciones a la JEP, siguen ofreciendo un importante respaldo al Acuerdo, lo que demuestra que su función trascendió la presidencia de Juan Manuel Santos y se relaciona directamente con lo acordado.

El apoyo de este grupo de países fue fundamental luego de la victoria del "no" en el plebiscito. La mayoría de reacciones, aunque aceptaban los resultados democráticos, tendían a expresar el deseo de que se encontraran nuevos caminos para alcanzar la paz. Así lo demuestran el comunicado de la Secretaría de Relaciones Exteriores mexicana en el que se expresaba que "México hace votos porque Colombia siga explorando todas las avenidas posibles para avanzar de manera unida hacia un futuro de paz y prosperidad"; las declaraciones del Gobierno de Noruega acerca de la necesidad de seguir negociando a pesar de la "decepción" por los resultados; o la reacción del entonces presidente francés François Hollande que destacaba la "valentía política" de Santos por buscar una paz negociada (Dinero, 2016). De forma casi unánime la comunidad internacional obvió los resultados del plebiscito y se dispuso a contribuir para hallar nuevos caminos para alcanzar el Acuerdo. 
Lo anterior resulta peculiar puesto que permite entrever que los actores internacionales no solamente estaban actuando en Colombia como una respuesta ante la petición del Gobierno nacional, sino que perseguían una agenda particular: la promoción del Acuerdo de paz. En esa relación estratégica estaban participando conjuntamente el Gobierno colombiano (principal impulsor de la internacionalización), diversos actores internacionales (que, además de ser invitados por el Gobierno, intentaban contribuir a la consecución de los diálogos) y la población colombiana que con el plebiscito demostró que había profundas dudas sobre lo acordado.

Aun actores no estatales pudieron haber sido importantes para respaldar el proceso. El anuncio, cinco días luego de celebrado el plebiscito, de que el presidente Santos iba a ser galardonado como el Nobel de Paz sirvió para reavivar (así fuera de forma involuntaria) la posibilidad de renegociar. Como él mismo lo expresó en la ceremonia: "En un momento en que nuestro barco parecía ir a la deriva, el premio fue el viento de popa que nos impulsó para llegar a nuestro destino: jel puerto de la paz!" (Lafuente, 2016). Otros actores no gubernamentales como el Comité Internacional de la Cruz Roja también ofrecieron su apoyo a la negociación (Pentin, 2018).

La inclusión de la comunidad internacional en las negociaciones entonces fue también capitalizada en el discurso interno para afianzar la confianza de la población. Entre el 2008 y el 2015, más del 60\% de los colombianos apoyaba la participación de actores internacionales en las negociaciones de paz, ${ }^{6}$ por lo que, puede inferirse, que desde el ejecutivo esto se leyó como una forma de influenciar la opinión pública. Sin embargo, si se considera que para el 2016 cerca del $60 \%$ de los colombianos no apoyaban el Acuerdo de Paz y que el 66\% decía sentir desconfianza frente al Alto Comisionado para la Paz, ${ }^{7}$ puede considerarse entonces que la estrategia de legitimar el proceso a través de actores internacionales no estaba resultando muy exitosa.

6 Esto según los datos del proyecto Las Américas y el Mundo (2008; 2010; 2012; 2014).

7 Esto según el Barómetro de las Américas (2017). 
Aun así, casi siempre hubo presencia de actores internacionales en momentos trascendentales de la negociación. Por ejemplo, cuando se anunció la consecución de un acuerdo en junio del 2016, en La Habana estuvieron presentes Ban Ki Moon (entonces secretario general de la ONU), los presidentes de México, de El Salvador y de los países acompañantes y garantes, y la CELAC representada por República Dominicana. Asimismo, durante la firma del Acuerdo en Cartagena estuvo presente la ONU, el entonces secretario de Estado de Estados Unidos (John Kerry), los cancilleres de Cuba, Noruega, España y Paraguay, y los presidentes de México, Cuba, Bolivia, El Salvador, Guatemala, Perú, Brasil y Chile. Estos actos, si bien tienen un limitado alcance, pretendían solidificar la imagen de un acuerdo robusto y sólido. Sin embargo, los esfuerzos legitimadores resultaron opacados por el rechazo amplificado de la ciudadanía.

La estrategia de legitimación interna a través de la comunidad internacional también enfrentaba al país al dilema de tener, por un lado, a organizaciones internacionales y países con alta legitimidad interna como la ONU y los Estados Unidos que, como lo muestra la figura 3, en el 2010 eran identificados por más del 50\% de los colombianos como los llamados a participar en la solución del conflicto y, por otro, a Venezuela y Cuba, que eran los países con peor imagen entre la población (profundizada, además, por su participación en unos diálogos que una buena parte de la población percibía de forma negativa). Es decir, los intereses del Estado colombiano al formular esta interacción estratégica podían, en ocasiones, reñir entre sí, dado que, aunque se necesitaba de la presencia de Venezuela y Cuba para consolidar los diálogos y generar confianza entre las partes negociadoras, también se buscaba, a través de esa internacionalización, legitimar el proceso, lo cual podía resultar difícil dado que, como ya fue mencionado, actores de la política doméstica construyeron un discurso que anatematizaba a estos dos países por sus proyectos políticos y encontraban en ellos una excusa para desvirtuar los diálogos de paz (Caicedo, 2016). 
Figura 3. ¿Qué actor debería participar en la solución del conflicto colombiano?

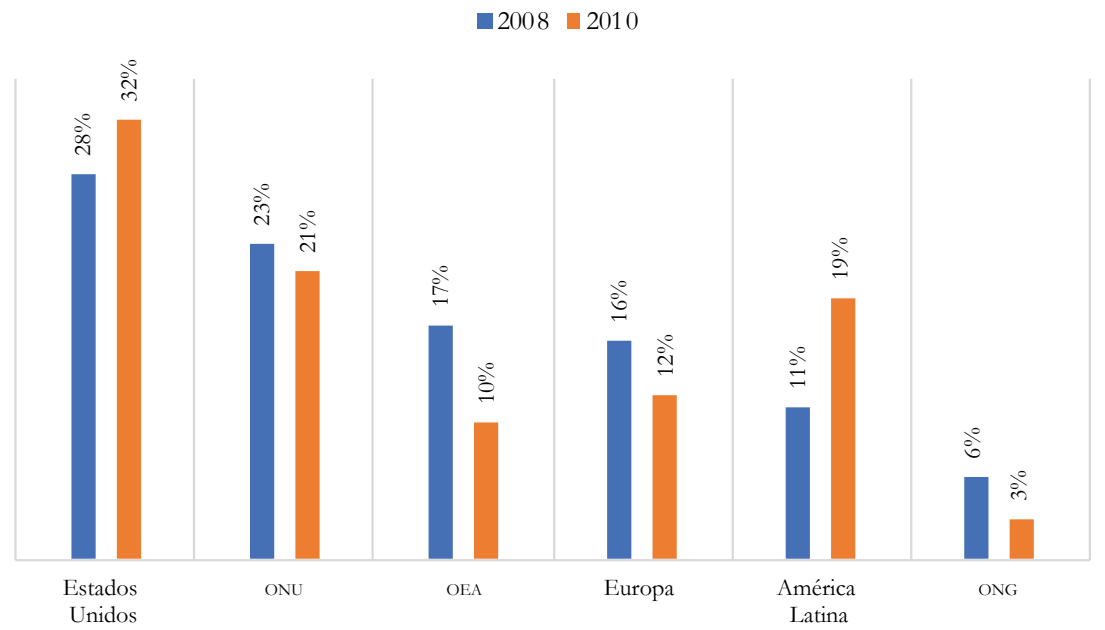

Fuente: Elaboración propia a partir de los datos del proyecto Las Américas y el Mundo (2008; 2010).

Aunque resulta complejo determinar qué parte de la opinión de los colombianos sobre el Acuerdo descansaba sobre su percepción de la participación que tenían los actores internacionales en el proceso, lo que sí puede afirmarse es que el Gobierno colombiano instrumentalizó el apoyo internacional y lo internalizó como una demostración de las fortalezas del Acuerdo. El mismo Juan Manuel Santos expresó que "(...) sin ese respaldo internacional (...) el proceso de paz no tendría éxito" (El Espectador, 2015) y que una buena parte de la credibilidad del mismo dependía de esos actores (Noticias RCN, 2015). Es decir que, más allá del éxito o no de esa estrategia de legitimación, es importante resaltar que, en el discurso político interno, lo internacional se asumió como una muestra incontrovertible del valor del Acuerdo.

Así, puede evidenciarse que la presencia de actores internacionales estaba buscando recursos simbólicos para capitalizarlos a nivel doméstico. La internacionalización de la paz, entonces, fue una forma de legitimar a nivel doméstico un proceso de paz que se enfrentaba a fuertes cuestionamientos por parte de un sector político. 


\section{Implementación de lo acordado}

En este grupo deben incluirse aquellos actores que, aunque no necesariamente participaron en medio de los diálogos, han contribuido a que lo que se pactó en La Habana pueda ser aplicado en la realidad. Estos, entonces, se encuentran directamente en la etapa del "posacuerdo". Nuevamente, es posible que algunos miembros de esta categoría se traslapen con otras antes mencionadas; no obstante, es posible identificar algunos, como la ONU, que empezaron su participación directa en el Proceso justo luego de que se le incluyera en el mecanismo de "monitoreo y verificación". Involucrar a la mayor organización intergubernamental existente en el proceso de implementación implicaba también dotar de legitimidad un proceso de paz cuestionado ampliamente por la oposición política.

Asimismo, es menester recordar que la Secretaría General de la ONU es depositaria de la declaración unilateral del Estado colombiano en la que este se compromete a cumplir lo acordado. Eso implica que, como lo afirma Rojas (2019), Santos comprometió al país ante la comunidad internacional a implementarlo. En ese sentido, el sistema internacional sirvió para que lo blindara y le resultara más complejo a su sucesor dar marcha atrás a ese "legado".

Con respecto a la financiación del posacuerdo, Rojas (2019) también menciona que se presupuestaban 130 billones de pesos para los quince años de implementación que, en una buena parte, necesitan de la participación de actores internacionales. Así, organizaciones como la Agencia Presidencial de Cooperación Internacional de Colombia (APC-Colombia) debieron centrar sus esfuerzos en la consecución de fondos para llevar a la realidad lo acordado.

La Unión Europea ha participado en ese proceso: en 2016 creó el Fondo Fiduciario para el Posconflicto en Colombia, con noventa millones de euros, y ha participado en proyectos de cooperación a fin de solidificar la presencia institucional del Estado colombiano (García Duque \& Martínez, 2016). Asimismo, países como Reino Unido, Canadá, Suecia, Alemania, Noruega, Suiza, Irlanda, Emiratos 
Árabes Unidos y Estados Unidos han realizado donaciones destinadas a implementar el Acuerdo (El Colombiano, 2016; El Heraldo, 2017; El Tiempo, 2017). La ONU, por su parte, también ha entregado dinero a fin de financiar la JEP (El Heraldo, 2018). Además de eso, los expresidentes de España y Uruguay (Felipe González y José Mujica, respectivamente) fueron designados, en marzo del 2017, como verificadores internacionales de lo pactado.

Si bien actores como la Unión Europea y Estados Unidos habían estado haciendo aportes a la resolución del conflicto armado colombiano décadas atrás de la firma del Acuerdo, como lo manifiestan Agudelo y Riccardi (2019), hubo una profundización del apoyo monetario y técnico por parte del primero y un notable cambio de enfoque en el caso del segundo. Solo con la llegada al poder de Barack Obama y con la búsqueda constante de apoyo para el posconflicto que realizó Santos fue posible que se reconociera la necesidad de remodelar el "plan de cooperación norteamericano que pasó de ser Plan Colombia a Plan Paz Colombia" (p. 117).

Con respecto a la Unión Europea, estos autores muestran que, aunque en los años previos a los diálogos de paz tanto esa organización como sus países miembros habían sido críticos con el enfoque de cooperación "dura" que había sostenido Estados Unidos frente a Colombia, entre el 2012 y el 2016 los niveles de cooperación bilateral aumentaron casi el doble (de 271,4 millones de dólares a 514,6 millones de dólares). Es necesario remarcar que las donaciones destinadas al cumplimiento de los acuerdos son uno de los pilares fundamentales de la estrategia de internacionalización en la fase de implementación. No obstante, el rol de la comunidad internacional en esta fase no se agota en el desembolso de dinero. La Ayuda Popular Noruega, por ejemplo, ha participado en proyectos de desminado y la cooperación de la Unión Europea ha incluido la solidificación institucional y la cooperación técnica como pilares de la estrategia de construcción de paz (Galeano et al., 2019).

La ONU actúa como una de las principales impulsoras de la implementación a través de la Misión de Verificación que se estableció en el 2017 
con la Resolución 2366 del Consejo de Seguridad y se ha renovado los dos años siguientes por petición del presidente Duque. Antes ya se había establecido, en 2016, una misión encargada del componente internacional y coordinadora del mecanismo tripartito de monitoreo y verificación (MMV) de la dejación de armas y la aplicación del cese al fuego y de las hostilidades, además de informar sobre el cumplimiento de los compromisos pactados (Informe Secretario General al Consejo de Seguridad, S/2016/729, 2016).

Luego de finalizado el proceso de dejación de armas, el entonces presidente Santos solicitó el establecimiento de una segunda misión que tuviera por mandato verificar la implementación de los puntos 3.2 y 3.4 del Acuerdo Final (relativos a la reincorporación de los excombatientes a la vida civil y las garantías de seguridad y lucha contra organizaciones criminales). En la Resolución 2366, el Consejo de Seguridad determinó que, desde el 26 de septiembre de 2017 (después de finalizada la primera misión), comenzaría todas las actividades de verificación durante doce meses e informaría al Consejo sobre la ejecución del mandato cada noventa días. Según el Informe del Secretario General al Consejo de Seguridad (S/2017/745) (2017), el mandato de la Misión de Verificación se limita a

verificar (...) la reincorporación de las FARC-EP a la vida política, económica y social, y la implementación de garantías de seguridad personal y colectiva y de programas integrales de seguridad y protección para las comunidades y organizaciones en los territorios, así como la verificación necesaria a nivel regional y local (Párrafo 5).

Finalmente, en las resoluciones 2435 del 2018 y 2487 del 2019, en respuesta a solicitudes hechas por el presidente Duque, el Consejo de Seguridad decidió prorrogar la Misión hasta el 25 de septiembre del 2019 y 2020, respectivamente. La diferencia principal entre las dos misiones que se han establecido radica en el hecho de que la primera estaba destinada, principalmente, a verificar el punto 3.1 del Acuerdo Final relativo al cese al fuego y las hostilidades mientras que, como ya se mencionó, la Misión de Verificación tiene por objetivo verificar la 
implementación de los puntos 3.2 y 3.4. Asimismo, como lo menciona el Informe S/2017/745 (2017), la segunda ya no incluye tareas de coordinación ni tareas operacionales, por lo que está dirigida exclusivamente a la verificación.

En el proceso de implementación, la comunidad internacional ha participado, principalmente, a través de la cooperación (que implica, conjuntamente, las donaciones para la puesta en marcha del Acuerdo y la cooperación técnica) y, particularmente la ONU, con las dos misiones de verificación e implementación del cese al fuego y las hostilidades, y de la reincorporación y garantía de los excombatientes. La formulación de la política exterior también estaba en búsqueda de recursos materiales con el objetivo de poner en marcha un ambicioso proyecto político que, sin estos fondos, resultaría irrealizable para el Estado colombiano.

\section{Blindaje internacional y tensiones políticas: ¿hacia la desinternacionalización de la paz?}

La multiplicidad de actores internacionales que participaron en las negociaciones y en su posterior implementación ha terminado por forjar un entramado político, económico y jurídico que le impide al Gobierno colombiano tomar decisiones sin que produzcan la respuesta de estos. Los países que financiaron el Fondo Multidonante de las Naciones Unidas para el Posconflicto, por ejemplo, solicitaron al presidente Duque, en julio del 2018, cumplir con los acuerdos (Colprensa, 2018). Asimismo, los embajadores de Noruega, Suiza y Suecia pidieron claridad a la Oficina del Alto Comisionado para el Posconflicto sobre la utilización de los dineros del Fondo Colombia Sostenible por la no renovación de un contrato (ElEspectador, 2018b). Eso, más allá de una simple formalidad, permite entrever que el recibimiento de los fondos implica responsabilidades de cumplimiento y, por ende, una suerte de veeduría internacional sobre la implementación de lo pactado. 
De la misma forma, la Misión de Verificación de la ONU ha sido muy activa al pronunciarse sobre asuntos coyunturales que, aunque se encuentran dentro de su mandato, pueden llegar a colisionar con el partido del presidente Duque. Ejemplos de ello son sus pronunciamientos frente al caso de Seuxis Paucis Hernández Solarte, alias Jesús Santrich, su apoyo a la JEP luego de las objeciones a la ley estatutaria presentada por el presidente Duque y su constante rechazo a los asesinatos de líderes sociales y excombatientes de las FARC-EP (Misión de Verificación de la ONU en Colombia, 2018b; 2019a; 2019b). En 2018, cuando Iván Duque no se había posicionado, el Centro Democrático (2018) rechazó el comunicado de la Misión de Verificación y expresó que "no aceptaba sus exigencias", lo que pone en evidencia tensiones entre el partido de gobierno y el organismo internacional.

Estas tensiones se han ido exacerbando durante el Gobierno de Iván Duque, como se hizo manifiesto con el pronunciamiento de Agnès Callamard, relatora especial sobre ejecuciones extrajudiciales, sumarias o arbitrarias, luego de que un excombatiente de las FARC-EP, Dimar Torres, fuera torturado y asesinado por el Ejército colombiano. Callamard expresó que el Gobierno colombiano estaba incitando la violencia contra los desmovilizados y que parecía estar despreciando las garantías establecidas en el Acuerdo Final. Ante esto, el expresidente Álvaro Uribe Vélez respondió diciendo que la ONU debía "respetar" al Gobierno y cuestionó su papel de verificadora (El Tiempo, 2019b). De la misma forma, Emilio Archila, el Alto Consejero para el Posconflicto, dijo que lo dicho por la ONU era "irresponsable" y que estaban considerando la posibilidad de no responder al formulario que se les había solicitado (Revista Semana, 2019). Presidencia, a través de un comunicado, consideró que era un informe "prematuro y malintencionado" (ElTiempo, 2019c).

Las presiones no solo han venido por parte de la ONU; setenta y nueve congresistas estadounidenses enviaron una carta a Mike Pompeo en la que manifestaban que la implementación del Acuerdo estaba "siendo obstaculizada por la burocracia y decisiones por parte de la administración de Duque” (Gómez, 2019). Si bien esta no es la posición 
oficial del Gobierno estadounidense, sí representa las dificultades a las que se enfrenta el Ejecutivo colombiano cada vez que actúa en detrimento de los Acuerdos.

Aunque las confrontaciones hasta ahora no se han materializado en escenarios distintos al discurso, Castrillón (2019) hizo público que una delegación de la ONU, conformada por seis agencias que funcionan en Colombia, fue recibida con desdén en la Cancillería y se le informó de la intención de reducir la presencia de la organización internacional en el país. Asimismo, en junio del 2019, se les avisó a los cuerpos diplomáticos que solo podían visitar las zonas de concentración de los excombatientes previa "aprobación del Gobierno", de miércoles a viernes y la segunda y cuarta semana de cada mes, lo que fue leído como una traba para la verificación del proceso de implementación (Gómez Polo, 2019).

La constante vigilancia internacional sobre la implementación del Acuerdo de Paz obligó al ejecutivo a moderar su discurso a nivel internacional. En su primera intervención ante la Asamblea General de la ONU, por ejemplo, dedicó una buena parte de esta a hablar de la importancia de continuar con su implementación. Sin embargo, con el tiempo, le ha resultado demasiado difícil hacer coincidir dos discursos distintos sin obtener la respuesta internacional, por lo que la confrontación resulta uno de los caminos posibles. Aún es demasiado pronto para pensar en ello, pero podría estarse asistiendo a una des-internacionalización de la paz a fin de lentamente quitarse de encima las ataduras que pudieron haberse creado en el pasado. Esto implicaría, necesariamente, privilegiar a los sectores más radicales del Centro Democrático y aislar nuevamente al país en el escenario global. La única forma de evitar el involucramiento constante de la comunidad internacional sería, en efecto, reducir los vínculos internacionales del país y cambiar el discurso a fin de privilegiar otros aspectos de la política exterior. 


\section{Conclusiones}

La internacionalización de la paz en Colombia, desde la teoría de los dos niveles de juego, puede entenderse como una interacción estratégica entre diversos actores del sistema internacional, las partes negociadoras y la población colombiana. El Gobierno colombiano, a sabiendas de las dificultades domésticas que enfrentaría para mantener en pie la negociación, acudió a la comunidad internacional a fin de afectar positivamente las percepciones de la población. En ese sentido, la formulación de la política exterior colombiana durante la presidencia de Juan Manuel Santos respondió a una necesidad doméstica (resolver el conflicto armado a través de un diálogo) y, de esta forma, los intereses del Estado a nivel internacional consistían, principalmente, en generar confianza entre las partes negociadoras; legitimar el proceso de paz entre la ciudadanía, y conseguir fondos para poner en marcha una política que, solo con los recursos domésticos, sería difícil de llevar a la realidad. Particularmente, la política exterior buscaba obtener, a través del involucramiento de actores internacionales, recursos (no necesariamente materiales) que le permitan al Gobierno solidificar los objetivos de la política doméstica.

Como lo demostró en su discurso de posesión para su segundo mandato, el objetivo principal del Gobierno de Santos fue acabar, a través del diálogo, con el conflicto armado que Colombia mantenía con las FARC-EP (ElHeraldo, 2014). A partir de esa meta esencialmente doméstica, el país estructuró una buena parte de su política exterior. Desde esa perspectiva, tanto los movimientos internacionales previos al proceso de paz, como los que se llevaron a cabo durante y después del Acuerdo respondían a una estrategia deliberada del ejecutivo para consolidar los diálogos, dotarlos de legitimidad a nivel interno y garantizar su implementación. El Gobierno colombiano era consciente de que sus acciones a nivel internacional provocaban reacciones a nivel doméstico y, por esa razón, decidió involucrar a otros actores a fin de solidificar el capital político con el que contaba (retado, además, por fuerte oposición). 


\section{6 / Reynell Badillo}

Entender la internacionalización del Acuerdo de Paz desde la teoría de los dos niveles de juego permite que no solo se analicen los resultados esperados por parte de los demás actores del sistema, sino que pueda pensarse en el cálculo estratégico también a partir de la respuesta de la población colombiana. Autores como Rodríguez (2017) han planteado que la estrategia de Santos, además de ser útil para mantener a flote los Diálogos, respondía también a los intereses políticos internos de este. Otros consideran que la internacionalización de la paz también produjo un cambio en la imagen internacional del país y permitió darle visibilidad internacional a lo conseguido en $\mathrm{La}$ Habana (Borda \& Morales, 2016; Sánchez \& Campos, 2019). Es decir, esta perspectiva permite afirmar que no solo se estaba involucrando a la comunidad internacional para alcanzar las metas del ejecutivo a nivel interno, sino que también la negociación era útil para alcanzar objetivos en la esfera internacional. Ese acercamiento es fundamental porque permite llegar a otra discusión acerca de los efectos inesperados de la internacionalización de asuntos que pertenecen, en esencia, a la esfera doméstica.

Por otro lado, el hecho de que algunos países financiadores del proceso de paz luego le pidieran, de manera pública, cuentas al Gobierno colombiano por lo realizado con sus fondos o de que, durante la negociación, el Gobierno de Venezuela exacerbara las tensiones fronterizas constantemente, son muestras de que el involucramiento de actores externos no necesariamente responderá siempre a las preferencias del Gobierno.

También resulta importante resaltar que la internacionalización del proceso de paz trajo consigo una suerte de "blindaje internacional" que complica la posibilidad de dar marcha atrás a lo acordado. Este blindaje puede verse desde acciones concretas como el depósito del Acuerdo Final como Acuerdo Especial ante el Consejo Federal Suizo en Berna (en el marco de las normas del Derecho Internacional Humanitario) y la entrega al Consejo de Seguridad de la ONU para que verifique su cumplimiento. Sin embargo, también el hecho de que diecinueve estados europeos hayan aportado recursos al Fondo Fiduciario Europeo para la Paz y el involucramiento mismo de los 
actores internacionales durante el proceso, lleva a la construcción de un entramado político que, ya sea a partir de la exigencia de cumplimiento jurídico o de la exigencia derivada de las relaciones políticas y económicas, produce una suerte de veeduría internacional de lo acordado (Colombia 2020, 2018).

La reacción de una buena parte de estos países y de la ONU ante las objeciones del presidente Duque a la Ley Estatutaria de la JEP son muestra de que el compromiso de la comunidad internacional no acabó con el periodo de Juan Manuel Santos. Es decir, a pesar de que el expresidente Santos era la figura impulsora del proceso de internacionalización de los diálogos de paz, ese "blindaje internacional" construido alrededor del Acuerdo no se restringía a su periodo presidencial, sino que se remite directamente a la implementación de lo firmado. Justamente por ello, y ante las confrontaciones discursivas que ha tenido el Gobierno de Iván Duque y varios de los representantes de su partido con la ONU y sus organismos, es posible vislumbrar una desinternacionalización de la paz, consistente en limitar la participación de actores internacionales y modificar la agenda a fin de que el posacuerdo no sea un elemento central de la política exterior.

Sobre la consolidación del proceso de paz, este puede haber sido uno de los principales elementos de la internacionalización si se considera que, luego de la experiencia de San Vicente del Caguán, la población colombiana permanecía reacia a zonas de distensión para diálogos de paz. Es decir, acudir a actores internacionales era casi un paso necesario puesto que difícilmente las negociaciones podían transcurrir en Colombia sin la suspicacia de los ciudadanos. Esta fase implicó la participación de actores que terminaron minando la legitimidad del proceso entre un sector de la oposición política (Venezuela y Cuba) y, en el caso del primero, que pudieron haber aprovechado su posición en la mesa para manejar las relaciones bilaterales.

Sobre la utilización del apoyo internacional como elemento legitimador del proceso, aunque es difícil considerar el éxito o fracaso de esta estrategia de forma específica ante la falta de datos que así lo consideren, el rechazo mayoritario al plebiscito del 2016 y la mala evaluación 
de algunos de los participantes internacionales en las negociaciones pueden evidenciar que no resultó suficiente para convencer a los colombianos de la robustez institucional del Acuerdo Final. Aun así, a través del discurso utilizado por el Gobierno puede inferirse que efectivamente llegó a pensarse que la comunidad internacional sería fundamental para convencer a la opinión pública. Finalmente, sobre la implementación del Acuerdo puede decirse que hay dos frentes principales. Por un lado, el de la cooperación económica y técnica que han hecho, principalmente, países a través de los canales bilaterales y organizaciones multilaterales como la Unión Europea. Por el otro, la presencia de la ONU a través de las dos misiones autorizadas por el Consejo de Seguridad.

\section{Referencias}

ABC Internacional. (2014, febrero 15). Uribe denuncia que «hay silencio cómplice con la dictadura de Venezuela». ABC. https://www.abc.es/ internacional/20140215/abci-uribe-denuncia-silencio-complice201402141747.html

Agudelo, J., \& Riccardi, D. (2019). La cooperación internacional para la paz en Colombia: los casos de Estados Unidos y de la Unión Europea (1998-2016). Geopolitica(s): Revista de estudios sobre espacio y poder, 10(1), 107-134. https:/doi.org/10.5209/GEOP.61477

Allison, G. T., \& Zelikow, P. (1999). Essence of Decision: Explaining the Cuban Missile Crisis. Nueva York: Pearson Longman.

Alons, G. C. (2007). Predicting a State's Foreign Policy: State Preferences between Domestic and International Constraints. Foreign Policy Analysis, 3(3), 211-232. https://doi.org/10.1111/j.1743-8594.2007.00048.x

Asamblea General de las Naciones Unidas. (2019, febrero 4). Situación de los derechos humanos en Colombia: Informe del Alto Comisionado de las Naciones Unidas para los Derechos Humanos (A/HRC/40/3/ Add.3). ONU. http://www.hchr.org.co/index.php/informes-y-documentos/informes-anuales/9017-informe-del-alto-comisionado-delas-naciones-unidas-para-los-derechos-humanos-sobre-la-situacionde-derechos-humanos-en-colombia-durante-el-ano-2018 
Barómetro de las Américas. (2017). Colombia 2016/17. [Data set]. Disponible en: http://datasets.americasbarometer.org/database/files / 1966987763Colombia\%20LAPOP\%20AmericasBarometer\%202016 \%20V1.0_W.dta

Bermúdez, C. (2012). Colombia en los recientes esfuerzos de integración regional latinoamericana. Perspectivas Internacionales, 8(2), 62-89.

Betz, J., \& Hanif, M. (2010). The Formation of Preferences in Two-level Games: An Analysis of India's Domestic and Foreign Energy Policy. GIGA Working Papers. GIGA German Institute of Global and Area Studies. https: / / core.ac.uk/download/pdf/6762335.pdf

Borda, S. (2007). La internacionalización del conflicto armado después del 11 de septiembre: ¿La ejecución de una estrategia diplomática hábil o la simple ocurrencia de lo inevitable? Colombia Internacional, 65(1), 66-89. https://doi.org/10.7440/colombiaint65.2007.03

Borda, S., \& Gómez, S. (2017). La internacionalización del proceso de paz de La Habana: del aislacionismo a la contención. En A. Tickner \& S. Bitar (Eds.), Nuevos enfoques para el estudio de las relaciones internacionales en Colombia (pp. 213-237). https://doi.org/10.7440/2017.51

Borda, S., \& Morales, M. (2016). Colombia: la internacionalización de la paz. En F. Fàbregues, \& O. Farrés, Anuario Internacional CIDOB 2016-17 (pp. 239-247). Barcelona: Barcelona Centre for International Affairs (CIDOB).

Botero, F., \& Tickner, A. B. (2009). Colombia y el mundo, 2008. Opinión pública y politica internacional. Bogotá: Universidad de los Andes, Facultad de Ciencias Sociales, Departamento de Ciencia Política, Escuela de Gobierno Alberto Lleras Camargo, Centro de Estudios Socioculturales e Internacionales, Ediciones Uniandes.

Botero, F., \& Tickner, A. B. (2011). Colombia y el mundo, 2010. Opinión pública y política internacional. Bogotá: Universidad de los Andes, Facultad de Ciencias Sociales, Departamento de Ciencia Política, Centro de Estudios Socioculturales e Internacionales, Ediciones Uniandes.

Caicedo, J. (2016). “¿Ésta es la paz de Santos?”: el partido Centro Democrático y su construcción de significados alrededor de las negociaciones de paz. Revista CS, 19, 15-37. https:/doi.org/10.18046/recs.i19.2136

Castrillón, G. (2019, mayo 26). Un encuentro poco diplomático entre la Cancillería y la ONU. Colombia 2020, El Espectador. https://www.ele- 
spectador.com/colombia2020/politica/un-encuentro-poco-diplomatico-entre-la-cancilleria-y-la-onu-articulo-862657

Centro Democrático. (2018, junio 26). Comunicado / Frente a pronunciamiento de la Misión de verificación de la ONU. Centro Democrático. https:// www.centrodemocratico.com/? $\mathrm{p}=2134$

CNN en Español. (2017, agosto 16). "Lloramos por ti, Venezuela": la fuerte crítica de Santos a Maduro. CNN en Español. https://cnnespanol.cnn. com/2017/08/16/columna-santos-venezuela-maduro-dictaduracritica/

Colprensa. (2018, julio 12). ONU y países que donaron a Colombia tras el proceso de paz piden a Duque cumplir con los acuerdos. El País. https://www.elpais.com.co/proceso-de-paz/onu-y-paises-que-donaron-a-colombia-tras-el-piden-a-duque-cumplir-con-los-acuerdos.html

Colombia 2020. (2018, agosto 6). Europa convoca a vigilar la implementación de la paz en Colombia. Colombia 2020. https:/ / colombia2020. elespectador.com/pais/europa-convoca-vigilar-la-implementacionde-la-paz-en-colombia

Colombia en Transición. (2019, marzo 16). La comunidad internacional, el gran apoyo de la JEP. Colombia 2020. https:// colombia2020.elespectador.com/jep/la-comunidad-internacional-el-gran-apoyo-de-la-jep

Consejo de Seguridad de las Naciones Unidas. (2016, agosto 18). Informe del Secretario General al Consejo de Seguridad sobre la Misión de las Naciones Unidas en Colombia (S/2016/729). ONU. https://undocs. org/sp/S/2016/729

Consejo de Seguridad de las Naciones Unidas. (2017, agosto 30). Informe del Secretario General al Consejo de Seguridad sobre la Misión de Verificación de las Naciones Unidas en Colombia (S/2017/745). ONU. https://undocs.org/en/S/2017/745

da Conceição-Heldt, E., \& Mello, P. A. (2017). Two-Level Games in Foreign Policy Analysis. Oxford Research Encyclopedia of Politics. Nueva York, Oxford: Oxford University Press.

Dinero. (2016, octubre 3). Estas fueron las reacciones de la comunidad internacional ante el resultado del plebiscito. Dinero. https://www.dinero. $\mathrm{com} / \mathrm{pais} /$ articulo/reacciones-de-la-comunidad-internacional-anteresultado-del-plebiscito/233555 
Eichenberg, R. (1998). Domestic Preferences and Foreign Policy: Cumulation and Confirmation in the Study of Public Opinion. Mershon International Studies Review, 42(1), 97-105. https://doi.org/10.2307/254445

El Colombiano. (2016, agosto 24). Regiones y cooperación, factores clave para consolidar la paz. El Colombiano. https://www.elcolombiano. $\mathrm{com} /$ colombia/acuerdos-de-gobierno-y-farc/regiones-y-cooperacionfactores-clave-para-consolidar-la-paz-AC4848442

ElEspectador. (2013a, marzo 25). Diálogos de paz con Farc "fundamentales" para Ecuador. ElEspectador. https://www.elespectador.com/noticias/ paz/dialogos-de-paz-farc-fundamentales-ecuador-articulo-412395

El Espectador. (2013b, junio 3). Controversia por interés de Colombia en la OTAN. El Espectador. https://www.elespectador.com/noticias/temadeldia/controversia-interes-de-colombia-otan-articulo-425758

El Espectador. (2015, febrero 23). Santos defendió presencia de Bernard Aronson en proceso de paz. El Espectador. https://www.elespectador.com/noticias/politica/santos-defendio-presencia-de-bernardaronson-proceso-de-articulo-545693

ElEspectador. (2018a, noviembre 11). Duque destaca logros del Acuerdo de Paz y la Alianza del Pacífico. ElEspectador. https:/ / www.elespectador. $\mathrm{com} /$ noticias/politica/duque-destaca-logros-del-acuerdo-de-paz-yla-alianza-del-pacifico-articulo-823106

El Espectador. (2018b, abril 2). Noruega, Suiza y Suecia piden claridad en manejo del fondo para el posconflicto. ElEspectador. https://www.elespectador.com/noticias/paz/noruega-suiza-y-suecia-piden-claridaden-manejo-del-fondo-para-el-posconflicto-articulo-747699

ElEspectador. (2019, marzo 12). Gobierno defiende ante la ONU las objeciones a la estatutaria de la JEP. El Espectador. https:/ / www.elespectador. $\mathrm{com} /$ noticias/politica/gobierno-defiende-ante-la-onu-las-objecionesla-estatutaria-de-la-jep-articulo-844602

El Heraldo. (2014, agosto 7). Discurso de posesión del presidente Juan Manuel Santos 2014-2018. El Heraldo. https://www.elheraldo.co/ politica/discurso-de-posesion-del-presidente-juan-manuel-santos-2014-2018-162061

ElHeraldo. (2017, enero 18). Fondo de ONU para posconflicto en Colombia recibe 18,6 millones de dólares más. El Heraldo. https://www.elheraldo. co/colombia/fondo-de-onu-para-posconflicto-en-colombia-recibe186-millones-de-dolares-mas-320716 
El Heraldo. (2018, febrero 28). Contraloría vigila donación de US $\$ 4,5$ millones de la ONU a la JEP. El Heraldo. https://www.elheraldo.co/ colombia/contraloria-vigila-donacion-de-us45-millones-de-la-onula-jep-464358

García Duque, J., \& Martínez, J. D. (2016, diciembre 12). Fondo fiduciario, nuevo apoyo de la Unión Europea a la paz de Colombia. El Tiempo. https://www.eltiempo.com/archivo/documento/CMS-16771157

El Tiempo. (2017, noviembre 11). Ratifican en Medio Oriente millonaria donación para el posconflicto. ElTiempo. https://www.eltiempo.com/ politica/gobierno/santos-llega-a-emiratos-arabes-y-firma-apoyomillonario-para-el-posconflicto-150276

El Tiempo. (2019a, marzo 15). Canciller explicó a Fiscal de la CPI razones de objeciones a la JEP. El Tiempo. https://www.eltiempo.com/politi$\mathrm{ca} /$ gobierno/canciller-holmes-trujillo-explicara-en-cpi-razones-deobjeciones-a-ley-de-la-jep-337764

El Tiempo. (2019b, junio 6). 'Lo que hay que decirle a Naciones Unidas es que respeten': Uribe. El Tiempo. https://www.eltiempo.com/politica/ partidos-politicos/alvaro-uribe-dice-que-hay-que-decirle-a-la-onuque-respeten-371958

El Tiempo. (2019c, junio 5). Informe de relatores de ONU es "prematuro y malintencionado" Gobierno. ElTiempo. https:/ /www.eltiempo.com/ justicia/conflicto-y-narcotrafico/gobierno-critica-informe-de-onusobre-asesinatos-de-desmovilizados-371318

Fisas, V. (2013). Anuario de procesos de paz. Barcelona: Escola de Cultura de Pau, Universitat Autónoma de Barcelona.

Frieden, J. A. (1999). Actors and Preferences in International Relations. En D. A. Lake, \& R. Powell (Eds.), Strategic Choice and International Relations (pp. 39-76). Princeton: Princeton University Press.

Frieden, J. A., Lake, D. A., \& Schultz, K. A. (2013). World Politics. Nueva York: W. W. Norton.

Galeano, H., Badillo, R., \& Rodríguez, M. (2019). Evolución de la política exterior de Colombia en el período 2002-2018. OASIS, 29, 57-79. https://doi.org/10.18601/16577558.n29.04

Garcé, A., \& López, C. (2014). La política exterior como política pública: Ideas, intereses e instituciones. Debates teóricos recientes desde la Ciencia Política. Conferencia presentada en la Conferencia FLACSO-ISA, Buenos Aires, Argentina. Disponible en http://web.isanet.org/Web/Conferences/ 
FLACSO-ISA\%20BuenosAires\%202014/Archive/f99a7c58-e4314c99-95df-719c3b8a7e5c.pdf

Goldstein, J. (1988). Ideas, institutions, and American trade policy. International Organization, 42(1), 179-217. https://doi.org/10.1017/ S0020818300007177

Gómez Maseri, S. (2018, junio 13). 'Ayuda de Estados Unidos a la paz está dando frutos'. El Tiempo. https://www.eltiempo.com/mundo/ eeuu-y-canada/balance-de-la-inversion-de-estados-unidos-a-la-pazde-colombia-229988

Gómez Maseri, S. (2019, mayo 25). Congresistas de EE. UU. piden presionar a Duque con acuerdo de paz. ElTiempo. https://www.eltiempo.com/ mundo/eeuu-y-canada/congresistas-de-estados-unidos-piden-presionar-a-ivan-duque-para-que-cumpla-con-paz-366544? fbclid=IwAR21J2JSvYJFrvoDk-zJyquBx7TuVGgT6ebt6y_3yLnRYS8-PJPSMN5qDc Gómez Polo, G. (2019, junio 25). Molestia en cuerpo diplomático por restricción del Gobierno colombiano para visitar los ETCR. El Espectador. https://www.elespectador.com/noticias/politica/molestias-encuerpos-diplomaticos-por-supuesta-restriccion-para-visitar-los-etcrarticulo-867818?fbclid=IwAR1MIRb65X7w8Amis7VdTdBOTH zaAuWSFGCIwPvA4qLB5UMtQdTRCk2wcfc

Green M. (2001). Japan's Reluctant Realism. Nueva York: Palgrave Macmillan. Hermann, C., Kegley, C., \& Rosenau, J. (1987). New Directions in the Study of Foreign Policy. Londres: HarperCollins Publishers Ltd.

Hyde, S., \& Saunders, E. (2020). Recapturing Regime Type in International Relations: Leaders, Institutions, and Agency Space. International Organization, 74(2), 363-395. https: / / doi.org/10.1017/S0020818319000365

Jung In, J. (2006). The Link Between Domestic Political Institutions and Commitments to Tariff Reduction Agreement. The Korean Journal of International Relations, 46(5), 95-113. https://doi.org/10.14731/ kjis.2006.12.46.5.95

Kissinger, H. (1966). Domestic Structure and Foreign Policy. Daedalus, 95(2), 503-529. www.jstor.org/stable/20026982

Koch, M. (2015). A Liberal Perspective: The Role of Interest Groups in US Foreign Policy Towards Iran. Conferencia presentada en la ECPR General Conference, Berlín, Alemania. Disponible en https: / / ecpr.eu/Filestore/ PaperProposal/63c3ea1d-6a0e-4556-a2bc-c1d0f868729d.pdf 
Lafuente, J. (2016, diciembre 10). Juan Manuel Santos, tras recibir el Nobel de la Paz: "Hay una guerra menos en el mundo y es la de Colombia". El País. https://elpais.com/internacional/2016/12/10/actualidad/1481370447_133792.html

Las Américas y el Mundo. (2008). Colombia 2008 [Data set]. https://url2. $\mathrm{cl} / \mathrm{XMddL}$

Las Américas y el Mundo. (2010). Colombia 2010 [Data set]. https://url2. $\mathrm{cl} / \mathrm{vMGNX}$

Las Américas y el Mundo. (2012). Colombia 2012 [Data set]. https://url2. $\mathrm{cl} / 7 \mathrm{vKUa}$

Las Américas y el Mundo. (2014). Colombia 2014 [Data set]. https://url2. $\mathrm{cl} / \mathrm{ZWr} 1 \mathrm{i}$

Márquez, M. (2015). Colombia, Venezuela y Ecuador: cooperación y coexistencia de cara al posacuerdo. En E. Pastrana, \& H. Gehring, La politica exterior colombiana de cara al proceso de pazy el posconflicto (pp. 539566). Bogotá: Editorial Pontificia Universidad Javeriana y Konrad Adenauer Stiftung.

Misión de Verificación de la ONU en Colombia. (2018a, julio 5). La ONU rechaza y condena los asesinatos a las y los defensores de derechos humanos y líderes y lideresas en Colombia. 5 de julio de 2018. Recuperado de https://colombia.unmissions.org/la-onu-rechaza-ycondena-los-asesinatos-las-y-los-defensores-de-derechos-humanos$\mathrm{y}-1 \% \mathrm{C} 3 \%$ ADderes-y

Misión de Verificación de la ONU en Colombia. (2018b, octubre 5). Declaración conjunta de la Misión de Verificación de la ONU en Colombia y de la Oficina en Colombia de la Alta Comisionada de las Naciones Unidas para los Derechos Humanos. Misión de Verificación de la ONU en Colombia. https:// colombia.unmissions.org/declaraci\%C3\%B3nconjunta-de-la-misi $\% \mathrm{C} 3 \% \mathrm{~B} 3 n$-de-verificaci $\% \mathrm{C} 3 \% \mathrm{~B} 3 n$-de-la-onuen-colombia-y-de-la-oficina-en-colombia

Misión de Verificación de la ONU en Colombia. (2019a, marzo 11). El Sistema de Naciones Unidas y la Misión de Verificación en Colombia reiteran la importancia del libre funcionamiento de la Jurisdicción Especial para la Paz como el principal instrumento de garantía del derecho a la justicia de las víctimas. https:/ / colombia.unmissions.org/el-sistemade-naciones-unidas-y-la-misi $\% \mathrm{C} 3 \% \mathrm{~B} 3 n$-de-verificaci $\% \mathrm{C} 3 \% \mathrm{~B} 3 n$-encolombia-reiteran-la-importancia-del 
Misión de Verificación de la ONU en Colombia. (2019b, mayo 17). Nota de prensa conjunta de la Misión de Verificación de la ONU en Colombia y de la Oficina en Colombia de la Alta Comisionada de las Naciones Unidas para los Derechos Humanos. https://colombia. unmissions.org/nota-de-prensa-conjunta-de-la-misi $\% \mathrm{C} 3 \% \mathrm{~B} 3 \mathrm{n}$-deverificaci $\% \mathrm{C} 3 \% \mathrm{~B} 3 \mathrm{n}$-de-la-onu-en-colombia-y-de-la-oficina-en

Moravcsik, A. (1993). Integrating International and Domestic Theories of International Bargaining. En P. Evans, H. Jacobson, \& R. Putnam (Eds.), Double-edged Diplomacy: International Bargaining and Domestic Politics (pp. 3-43). Berkeley: University of California Press.

Moravcsik, A. (1997). Taking Preferences Seriously: A Liberal Theory of International Politics. International Organization, 51(4), 513-555. https:/ / doi.org/10.1162/002081897550447

Noticias Caracol. (2015, mayo 28). Cuba y Noruega piden esfuerzos para salvar proceso de paz entre Gobierno y FARC. Noticias Caracolhttps:/ / noticias.caracoltv.com/colombia/cuba-y-noruega-piden-esfuerzospara-salvar-proceso-de-paz-entre-gobierno-y-farc

Noticias RCN. (2015, febrero 23). "Sin el respaldo internacional el proceso de paz no tendría éxito": Santos. Noticias RCN. https:/ / noticias.canalrcn. com/nacional-pais/sin-el-respaldo-internacional-el-proceso-paz-notendria-exito-santos

Noticias RCN. (2016, abril 28). Senado de Estados Unidos aprobó resolución de apoyo al proceso de paz. Noticias RCN. https:// noticias.canalrcn. com/nacional-dialogos-paz/senado-estados-unidos-aprobo-resolucion-apoyo-al-proceso-paz

Pastrana, E., \& Gehring, H. (2017). La politica exterior colombiana de cara al posconflicto. Bogotá: Editorial Pontificia Universidad Javeriana, Fundación Konrad Adenauer.

Pastrana, E., \& Vera, D. (2015). Política exterior colombiana, conflicto y posconflicto: algunas herramientas teórico-conceptuales para su análisis. En E. Pastrana, \& H. Gehring (Comps.), La politica exterior colombiana de cara al proceso de pazy el posconflicto (pp. 23-60). Bogotá: Editorial Pontificia Universidad Javeriana, Konrad Adenauer Stiftung. Pentin, N. (2018, diciembre 21). "Los defensores del acuerdo de paz merecen ser elogiados": CICR. Colombia 2020. https://colombia2020. elespectador.com/pais/los-defensores-del-acuerdo-de-paz-merecenser-elogiados-cicr 
Putnam, R. (1988). Diplomacy and Domestic Politics: The Logic of TwoLevel Games. International Organization, 42(3), 427-460. https://doi. org/10.1017/S0020818300027697

Ramírez, J., \& Espinoza, L. (2019). La prensa escrita y la politica exteriorperuana durante el diferendo marítimo con Chile. Lima: Fondo Editorial Pontificia Universidad Católica del Perú.

RCN Radio. (2013, junio 1). Venezuela dice que examina relaciones con Colombia. RCN Radio. https://www.rcnradio.com/internacional/ venezuela-examina-relaciones-con-colombia-69658

Resolución 2366/2017 del Consejo de Seguridad, S/RES/2366 (10 de julio de 2017), disponible en: https://undocs.org/S/RES/2366(2017)

Resolución 2435/2018 del Consejo de Seguridad, S/RES/2435 (13 de septiembre de 2018), disponible en: https://undocs.org/es/S/ $\mathrm{RES} / 2435(2018)$

Reyes, E. (2015, mayo 28). Cuba y Noruega, preocupados por la escalada del conflicto en Colombia. El Pais. https://elpais.com/internacional/2015/05/28/actualidad/1432787039_345848.html

Rodríguez, E. (2017). Internacionalización del conflicto, del acuerdo y del postacuerdo. Evolución, continuidades y rupturas de una estrategia. Análisis Politico, 30(90), 194-208. https://doi.org/10.15446/anpol. v30n90.68307

Rodríguez, G. (2014). Álvaro Uribe y Juan Manuel Santos: ¿una misma derecha? Nueva Sociedad, (254), 84-99.

Rojas, D. M. (2017). Estados Unidos en la construcción de la paz en Colombia. Análisis Politico, 30(91), 37-52. https://doi.org/10.15446/ anpol.v30n91.70263

Rojas, D. M. (2019). La política internacional de la administración Santos: entre los imperativos y las aspiraciones. OASIS, (29), 7-27. DoI: https://doi.org/10.18601/16577558.n29.02

Rosenau, J. N. (1967). Domestic Sources of Foreign Policy. Nueva York: Free Press.

Sánchez, F., \& Campos, S. (2019). La política exterior de Santos: estrategia y diplomacia por la paz. OASIS, 29, 81-104. https://doi. org/10.18601/16577558.n29.05

Revista Semana. (2019, junio 14). Sigue la violencia contra excombatientes de las FARC. Revista Semana. https://www.semana.com/nacion/articulo/ asesinan-a-otros-ex-combatientes-de-las-farc/619640 
Revista Semana. (2015, febrero 20). EE. UU. designa enviado especial para el proceso de paz. Revista Semana. https://www.semana.com/nacion/articulo/ee-uu-designa-enviado-especial-para-el-proceso-depaz/418515-3

Singer, D. (1961). The Level-of-Analysis Problem in International Relations. World Politics, 14(01), 77-92. https://doi.org/10.2307/2009557

Tickner, A. (2007). Intervención por invitación: Claves de la política exterior colombiana y de sus debilidades principales. Colombia Internacional, 65(2), 90-111.

Tickner, A., Cepeda, C., \& Bernal, J. L. (2013). Colombia y el mundo 2012. Opinión pública y política exterior. Bogotá: Universidad de los Andes, Facultad de Ciencias Sociales, Departamento de Ciencia Política, Ediciones Uniandes

Tickner, A., Cepeda, C., Rouvinski, V., \& Milanese, J. (2016). Colombia, Las Américas y el Mundo, 2015. Opinión pública y politica exterior. Bogotá: Ediciones Universidad de los Andes, Facultad de Ciencias Sociales, Departamento de Ciencia Política, Ediciones Uniandes.

Van Evera, S. (1985). Why Cooperation Failed in 1914. World Politics, 38(1), 80-117. https://doi.org/10.2307/2010352

Waltz, K. N. (1959). Man, the State and War: A Theoretical Analysis. Nueva York: Columbia University Press.

Waltz, K. N. (1979). Theory of International Politics. Berkeley: Addison-Wesley Publishing Company. 